\title{
REMOVER LOS OBSTÁCULOS. LOS INGENIEROS DE CAMINOS ESPAÑOLES Y SUS VISIONES DEL ESTADO DURANTE LA SEGUNDA MITAD DEL SIGLO XIX (1)
}

\author{
DARINA MARTYKÁNOVÁ \\ Universidad Autónoma de Madrid \\ darina.martykanova@uam.es
}

(Recepción: 15/05/2015; Revisión: 30/11/2015; Aceptación: 28/12/2015; Publicación: 02/12/2016)

1. L'État, C'EST NOUS.-2. Las VISIONES DEL Estado EN LA REVISTA DE OBRas

PÚBLICAS.-3. CONCLUSIÓN.-4. Bibliografía

\begin{abstract}
RESUMEN
Los ingenieros de caminos, integrantes del cuerpo técnico quizá más poderoso de la Administración española y el que mayor presupuesto manejaba, fueron a la vez producto y artífices de la construcción del Estado en la España decimonónica. Su autorrepresentación como defensores desinteresados del bien común fue una constante a lo largo del siglo. Quizá paradójicamente, las propuestas del liberalismo radical tuvieron numerosos partidarios en sus filas: la revista vinculada estrechamente al cuerpo ofrecía un amplio espacio a los promotores de las propuestas laissez-fairistas y, cuando llegaron a desempeñar cargos políticos de alto nivel durante el Sexenio democrático (18681874), varios personajes destacados del Cuerpo diseñaron e implementaron legislación y políticas que disminuían la intervención estatal y cedían protagonismo a la iniciativa privada. En este artículo se examinan las visiones del Estado que competían y se combinaban en el discurso de los ingenieros, prestando particular atención a trazar las

(1) Este trabajo se inscribe en el proyecto de investigación HAR2012-32713 del Plan Nacional de I+D+i y dentro del Career Integration Grant TECHDEM: Technocracy and Democracy: convergence, conflicts and negotiations. A comparative and global analysis of expert knowledge and political power (18th to 21th century), de la Acción Marie Curie de la Comisión europea. Contiene partes (no publicadas previamente) de la tesis doctoral de la autora: MARTYKÁNOVÁ (2010). Querría agradecer los comentarios de Juan Pan-Montojo, Florencia Peyrou y Hugo GARCía y una sugerencia bibliográfica muy útil de AINHOA GILARRANZ. Asimismo agradezco las sugerencias de los dos evaluadores.
\end{abstract}


dinámicas históricas y relacionarlas con los discursos políticos de la época y también con los discursos socio-profesionales de los ingenieros a nivel transnacional.

Palabras clave: Estado; ingenieros; escuela economista; progresismo; Sexenio; obras públicas.

\title{
REMOVING THE OBSTACLES. SPANISH "PONTS-ET-CHAUSSÉES" ENGINEERS' VISIONS OF STATE DURING THE SECOND HALF OF THE NINETEENTH CENTURY
}

\begin{abstract}
The «ponts-et-chaussées» engineers, members of one of the most powerful technical corps of the Spanish Administration, were at the same time products and agents of state-building in the nineteenth century Spain. Throughout the century, they represented themselves as defenders of public good. As striking as it may be, radical liberalism had many supporters among these state employees. The journal linked to the corps provided space for laissez-faire ideas and policy proposals. Moreover, when several corps engineers were appointed to influential government posts during the Sexenio democrático (1868-1874), some of them designed and put to practice laws and policies that reduced state intervention and tried to boost municipal and private initiative. This article explores the visions of state that competed and merged in the engineers' discourse. In particular, it traces historical changes in these visions and links them to period political discourses as well as to transnational socio-professional discourses of engineers.
\end{abstract} works.

Keywords: state; engineers; classical economics; progressism; Sexenio; public $* *$ El monopolio del Estado en punto
* obras públicas era un mal: ya no existe.
El Estado constructor era contrario a los sanos
principios económicos: ya no construye.
El Estado dedicando sus capitales a obras públicas es
todavía un sistema vicioso, y desaparecerá.
La asociación libremente constituida y de tal modo
organizada que los asociados posean, aun dentro de
ella misma, la mayor libertad posible, es la forma
perfecta por excelencia, y a ella pertenece el porvenir. (José Echegaray, 1868) (2)

(2) Preámbulo del Decreto-ley del 14 de noviembre de 1868, escrito por José Echegaray y publicado en AlzOLA Y MiNONDO (1994): 364-368. El decreto-ley está reproducido en MARTíNEZ 
El preámbulo del decreto-ley de Obras Públicas del 14 de noviembre de 1868 era una declaración de principios. Para su autor, el flamante director general de Obras Públicas José Echegaray, nombrado por el gobierno surgido de la revolución de septiembre de 1868 que posteriormente se conocería como La Gloriosa, suponía la culminación de muchos años de labor propagandística. Las convicciones de Echegaray no eran excepcionales entre los miembros del Cuerpo de ingenieros de caminos, de cuyas filas procedía. Sin ser necesariamente la corriente mayoritaria del pensamiento entre los ingenieros de caminos, la escuela economista, una corriente transnacional del pensamiento liberal representada, entre otros, por pensadores económicos franceses como Jean-Baptiste Sayy Frédéric Bastiat o británicos como John Stuart Mill, moldeó muchas de las opiniones expresadas en la Revista de Obras Públicas en los años cincuenta y sesenta del siglo XIX. Esta publicación era iniciativa de un grupo de ingenieros altamente politizados vinculados al progresismo; sin embargo, logró erigirse en portavoz informal del Cuerpo de ingenieros de caminos, canales y puertos, uno de los cuerpos facultativos del Estado más poderosos (3). Tuvo una repercusión más allá de los circuitos profesionales y aparece citada con frecuencia en otros periódicos de la época (4).

A primera vista puede resultar chocante encontrar tantos ingenieros de Estado entre los promotores de la escuela economista; esta corriente de pensamiento económico cuestionaba radicalmente las políticas intervencionistas del Estado en los ramos que eran competencia de estos empleados públicos, los cuales manejaban una dotación presupuestaria importante y gozaban de una situación administrativa privilegiada. ¿Podría entenderse esa paradoja como el triunfo de la identidad política sobre la identidad corporativo-profesional? No sería este el único caso en que los profesionales, una vez llegados al poder, adoptasen decisiones y medidas políticas que fueran en contra de lo que se entendía mayoritariamente como los intereses de la profesión. Entonces no habría más que constatar que en una situación de politización intensa, como pudo ser el Sexenio, estos sujetos actuaron simplemente movidos por su liberalismo radical, dejando de lado sus intereses corporativo-profesionales. No obstante, sorprende el peso que las visiones rupturistas de los «economistas» lograron alcanzar dentro de un cuerpo tan poderoso, autónomo y capaz de defender sus intereses como fue el Cuerpo de ingenieros de caminos durante los años $1850 \mathrm{y}$ 1860. ¿O acaso los ingenieros afectos a la escuela economista entendían su identidad corporativo-profesional de tal forma que el liberalismo radical podría llegar a entenderse como la visión del mundo más lógica? Si es así, habría que preguntarse si -al defender las ideas de la escuela economista- estos ingenieros de Estado promovían una visión particular del empleo público, por una parte, y

AlCuBILla (1887): 696-698.

(3) SÁENZ RidRUEJo (1993); MARTYKÁNOVÁ (2007).

(4) Por ejemplo, en La Época, La Iberia, La España, El Clamor público, La Esperanza, La Discusión, El Imparcial o Madrid científico. 
de la profesión de ingeniero, por otra, ambas coherentes con las medidas que proponían (5).

Desde que se consolidaran los cuerpos de ingenieros en el seno de la Administración central, muchos de sus miembros mostraron interés por los temas relacionados con el funcionamiento de la Administración, manifestando una actitud vigilante y crítica. A partir de los años 1850, los conflictos salieron de los despachos, dirimiéndose con una frecuencia cada vez mayor en la palestra pública. Los ingenieros no solamente se implicaron como individuos comprometidos con una u otra corriente política del momento, sino también como miembros de unos u otros grupos socio-profesionales. Sus revistas profesionales funcionaron como espacios de construcción identitaria, mediante declaraciones programáticas, pero también a través de polémicas internas y disputas con grupos y corrientes de pensamiento distintos. Además de tratar cuestiones técnicas y corporativas -o al mismo tiempo-, los ingenieros exploraron y aprovecharon este espacio para esbozar, precisar y discutir sus visiones de la Humanidad, del país, de su pasado, presente y futuro, así como del lugar que les correspondía como ingenieros.

En este artículo trataré una vertiente clave de estos debates, las visiones del Estado. Utilizando la Revista de Obras Públicas como fuente principal, Martínez Vara y Ramos Gorostiza han examinado las ideas económicas de los ingenieros de caminos (6). Beneficiándome de su valioso trabajo, además de mi propio análisis de dicha revista, pretendo ofrecer una perspectiva algo distinta, a la vez más estrecha y más amplia. En primer lugar, me ocuparé de examinar el papel que se asignaban los ingenieros a sí mismos dentro del Estado. En segundo lugar, me centraré en las visiones de Estado que desarrollaron los ingenieros, en las ideas sobre la naturaleza del Estado, sus atribuciones y su relación con los individuos. Mi análisis abarca un periodo que comienza en los años 1850 cuando se había consolidado plenamente el Cuerpo de caminos y apareció la Revista de Obras Públicas (1853); y concluye a finales del siglo XIX, cuando arrancó el discurso regeneracionista, cuya plasmación en el «debate hidrológico» supuso un hito, al reivindicar una involucración masiva del Estado en las obras hidráulicas.

En este trabajo, la Revista de Obras Públicas aparece en una doble dimensión: como espacio de construcción identitaria de los ingenieros de caminos y como la principal fuente primaria para la historiadora autora de este texto. En los dos sentidos se plantea una cuestión de máximo peso, la de la representatividad (7). Resultaría burdo ofrecer una visión homogénea del pensamiento y

(5) Agradezco al evaluador $n .^{\circ} 2$ sus observaciones con respecto a esta paradoja.

(6) Ramos Gorostiza y Martínez VARa (2008): 9-38.

(7) No es del todo fácil identificar el núcleo de los autores que impulsaron y sostuvieron la Revista de Obras Públicas. Se entiende que surgió como una iniciativa de un grupo de ingenieros jóvenes, algunos de ellos profesores de la Escuela de Caminos. Más sobre esta cuestión en 
del activismo político de los ingenieros, obviando las marcadas diferencias ideológicas existentes entre los hombres salidos de las escuelas de ingeniería españolas. Por lo tanto, los párrafos siguientes se refieren a la evolución de las tendencias principales que dominaron el debate en los espacios a los que he tenido acceso a través de las fuentes, teniendo en cuenta que la hegemonía no se establece según el número de los partidarios de cada corriente, sino según la voluntad y la capacidad de un grupo para hacer oír su voz e imponer sus convicciones, al lograr convertirse en representantes de sus compañeros silenciosos -o incluso discrepantes- en el ámbito institucional y en el escenario público.

\section{L'ÉTAT, C'EST NOUS}

Las visiones del Estado desarrolladas por los ingenieros de caminos se caracterizaron por la pluralidad y dinamismo histórico, a la vez que se observan varias constantes compartidas a través del tiempo y de las corrientes ideológicas. El papel del Cuerpo de caminos, su posición dentro del Estado, representa una de estas constantes, sobre la que merece la pena detenernos. En la España de la segunda mitad del siglo XIX, los cuerpos de ingenieros en general, y el Cuerpo de caminos en particular, se habían consolidado en una posición excepcional, parecida a la de los cuerpos de ingenieurs d'État franceses (8). Los miembros del Cuerpo de caminos lo tenían muy claro:

El aliciente que ofrece el dedicarse a la carrera de Ingeniero de Caminos, y las ventajas que realmente tiene el pertenecer a este Cuerpo, son: el objeto halagüeño y de verdadera utilidad para el país de los trabajos que tienen a su cargo los Ingenieros; la estabilidad que presenta la organización del Cuerpo; la seguridad que todos sus individuos tienen de no verse postergados o perjudicados por los que tal vez intentarán especular con las intrigas políticas o con la protección de influencias poderosas para anteponerse a los que más modestos, o menos ambiciosos se limitarán, como sucede, al cumplimiento estricto de sus deberes, oponiéndose a las aspiraciones ilegítimas sin temer los enemigos que pueda crearles esta conducta que exige el verdadero interés de los pueblos (9).

En primer lugar, los ingenieros de caminos españoles consideraron obvio, fuera de toda la duda, que su razón de ser, el trabajo que llevaban a cabo, era útil para el país, lo que les dotaba de una autoconfianza colectiva y de un sentido de legitimidad particularmente fuertes. Como he postulado en otro lugar, los ingenieros decimonónicos, retomando algunas pautas del discurso ilustrado, desarrollaron y difundieron exitosamente la visión del Estado como promotor

MARTYKÁNOVÁ (2007): 198, nota 14. Entre los directores figuraron Agustín Monterde o Eugenio Barrón Avignon.

(8) Sobre los ingenieros de ponts et chaussées franceses: PICON (1992).

(9) «Cuerpo de Ingenieros de caminos, canales, puertos y faros«, Revista de Obras Públicas, 23 (1856), 265-270. 
de obras públicas que conectó con varias corrientes políticas y logró situarse firmemente en el imaginario social español, en el que el Estado y las obras públicas aparecen inexorablemente ligados uno al otro (10).

Además, resaltaron los beneficios de la organización en cuerpos y su regulación a través del reglamento: la selección a través de una escuela especial -entendida como meritocrática-, la inamovilidad y la promoción por antigüedad les garantizaban un cierto grado de independencia de los poderes políticos. Es cierto que, frente a la mayoría de empleados públicos amenazados constantemente por el cese, los cuerpos de ingenieros disfrutaron de un alto grado de protección. En este sentido, constituyeron una excepción dentro de la Administración española de la época y eso contribuyó a hacer atractiva la carrera de ingeniero para hombres que buscaban seguridad y buenas retribuciones sin querer comprometer su independencia moral e ideológica, siempre y cuando sus familias dispusieran de medios suficientes para dotarles de una educación adecuada para el acceso a la Escuela de Caminos. Los ingenieros hacían alusiones frecuentes a los mecanismos de selección y funcionamiento de los cuerpos, ya que de allí derivaban criterios de legitimidad para sus pretensiones de representar el bien común, incluso a pesar de «los vaivenes políticos» (11).

Esta posición privilegiada dentro del aparato de la Administración central fue objetivo de duras críticas desde fuera, sobre todo por parte de los ingenieros industriales, que no disponían de un cuerpo del Estado. Guillermo Lusa y Manuel Silva han analizado en detalle la tensión entre la ingeniería como carrera de Estado y la idea de profesión liberal (12). Una vertiente de este debate concernía directamente al Estado: ¿deberían los cuerpos tener el monopolio del empleo público en el ramo? E incluso, ¿deberían existir estos organismos, asemejados por sus oponentes a los gremios del Antiguo Régimen? En general, el lugar que el cuerpo ocupaba en el entramado del Estado no fue objeto de crítica interna por parte de los miembros del mismo. Los ingenieros asumieron que, por las razones mencionadas arriba, ellos, más y mejor que nadie, eran el Estado, y defendieron la existencia de los cuerpos y sus atribuciones. En ocasiones plantearon esta defensa en términos generales, sin limitarse al contexto español: así, por ejemplo, criticaron la abolición del cuerpo civil portugués y su sustitución por ingenieros militares, alegando tanto la necesidad de conocimientos especializados en la ingeniería de carácter civil, como el sometimiento de los militares a la cadena del mando militar frente a la supuesta prevalencia

(10) PAn-Montojo y MartykánOVÁ (2012).

(11) Sobre estas cuestiones: MARTYKÁNOVÁ (2014). La crítica de la intervención política en el ramo: «Cuerpo de Ingenieros de Caminos, canales, puertos y faros», Revista de Obras Públicas, 23 (1856), 265; Alzola y MinONDo (1994): 447 y muchos otros textos.

(12) Silva SuÁrez y LuSa Monforte (2007). 
de la razón técnica entre los cuerpos de estatus civil (13). Asimismo, incentivar el desarrollo de la ingeniería como profesión liberal y apoyar la regulación del ejercicio privado no suponía para ellos cuestionar el papel de los cuerpos dentro del Estado central.

Solamente durante el Sexenio se pusieron en duda algunas de estas certezas a nivel interno, y aun así fue de forma más bien tímida. Las reformas liberalizadoras del Sexenio implicaron la posibilidad de que en un futuro lejano el cuerpo perdiera su razón de ser. Esto significaría que al menos algunos de los ingenieros de caminos afines a la escuela economista barajaron la posibilidad de realizar una misión de autodestrucción como cuerpo facultativo, aunque no como profesión de ingeniero de caminos, para la que preveían un futuro brillante con la expansión del sector privado y la multiplicación en este de las oportunidades dignas de los hombres de élite. Desde el primer instante, la Revista de Obras Públicas salió en defensa de las Bases Generales, subrayando que apoyaba la ley para el bien de la Nación a pesar de que pudiera perjudicar al Cuerpo de caminos y aunque pareciera que «en estas medidas de justicia se oculten los constantes y encarnizados enemigos de nuestro Cuerpo» (14). Los defensores contaban no solamente con que hubiera un largo periodo de transición en el cual la existencia de un cuerpo facultativo seguiría siendo imprescindible, sino que siempre iba a haber tareas de carácter técnico de las que el Estado tendría que hacerse cargo.

Nuestro Cuerpo perderá, y esto es lo lógico, su razón de ser, cuando el Estado no intervenga en las obras. Hasta llegar a ese caso tiene las mismas condiciones de existencia que el profesorado de nuestras Universidades, que nuestra magistratura y corporaciones análogas, para los cuales se pide una organización más o menos semejante a la nuestra por los mismos que quieren romper las trabas que hoy impiden entrar por la puerta del favor en el servicio que desempeñamos. El campo natural de nuestras funciones ¿se ensanchará o se estrechará con el decreto que hemos examinado? No es fácil responder a esta pregunta. Por un lado el Estado cede servicios y obras; por otro la descentralización y facilidades para promover trabajos de este género han de aumentar extraordinariamente el número de los que se inicien, en muchísimos de los cuales tiene que intervenir el Gobierno mientras se conserve la expropiación y el dominio público; es decir, que intervendrá en ellos aun cuando se adoptase la forma de gobierno más descentralizadora, y esto le ha de obligar a tener ingenieros, puesto que técnicas son las funciones que han de desempeñar. Sean los que quiera los empleados que conserve el Estado, es seguro que se han de organizar con condiciones de estabilidad y cierto orden para las entradas y los ascensos que haga a tales funcionarios independientes de la política y del capricho ministerial. (15).

(13) «Observaciones sobre el decreto expedido por el gobierno portugués disolviendo el Cuerpo de Ingenieros Civiles», Revista de Obras Públicas, 24 (1868): 281-284.

(14) «Bases generales para la nueva legislación de obras públicas», Revista de Obras Públicas, 23 (1868): 269-271.

(15) Ibid. 
No obstante, la radicalidad de la propuesta echegariana para el ramo de obras públicas no pasó desapercibida y dio pie a críticas demoledoras desde fuera. La Gaceta industrial rezaba:

Si ya no existe el monopolio del Estado en punto a obras públicas, porque era un mal; si el estado constructor era contrario a los sanos principios económicos, y ya no construye, ¿cómo el autor de preámbulo no ha sacado la consecuencia que de estos principios se deduce con respecto a los Cuerpos facultativos, y más especialmente al de Caminos, que es al que más directamente se refiere este caso? (16).

Los ingenieros industriales exigían poder competir por el trabajo en el sector público, reclamando que los servicios que estaban reservados solo para el Cuerpo de caminos fueran atribuibles por el Estado «al que ofrezca mayores garantías y le inspire mayor confianza, como lo hace con los demás servicios que tiene a su cargo» (17). Además, reivindicaron la regulación del ejercicio de la profesión (o de las profesiones) de ingeniero en el sector privado como medida para garantizar la capacidad, la calidad y el buen nombre de los ingenieros.

Desde estas posiciones acusaron a los ingenieros del Estado afectos a la escuela economista de oscilar deliberadamente entre la actitud proteccionista y la liberal, según su conveniencia, al defender criterios radicalmente opuestos para el sector privado y el público. Pintaron un cuadro en el que los ingenieros funcionarios aparecían como falsos liberales guiados por intereses corporativistas, en realidad más parecidos a los hombres del Antiguo Régimen. Haciéndoles representar el pasado, los ingenieros industriales se erigieron a sí mismos como los hombres del futuro, sin miedo a competir por el trabajo siempre y cuando el acceso al campo de juego estuviese permitido solo para aquellos que hubiesen demostrado su capacidad a través de una formación adecuada.

En su respuesta colectiva a través de la Revista de Obras Públicas, los ingenieros de caminos se aferraron a los pilares de su legitimidad corporativa, es decir, a la selección meritocrática y a la posición de independencia frente a las autoridades políticas de cada momento, percibidas como potencialmente corruptas, nepotistas e incapaces:

Pues si esta es la panacea que ha de remediar nuestros males, no merecía la pena de tanto escribir. Nosotros la hubiéramos formulado de este modo; puesto que las oposiciones para ser ingenieros duran cuatro o seis años y son un poco duras, vale más reemplazarlas por otras que se hagan en un par de días en las antesalas de los ministerios. Todo por el mayor bien del país (18).

(16) «Noticias varias», Revista de Obras Públicas, 23 (1868): 278-279. Polémica con la Gaceta industrial del 10 de noviembre 1868.

(17) Ibid. Véase también LuSA (1994).

(18) Ibid. 
El tono defensivo se percibe a lo largo del Sexenio, testimonio del cuestionamiento constante de la existencia de los cuerpos y de las atribuciones exclusivas:

No miras egoístas ni mezquinos intereses de clase, que sólo aviesas intenciones o lamentable ignorancia han podido atribuirnos, sino el amor al bien público que fue siempre móvil de todos nuestros actos y manantial fecundo de los relevantes servicios que ilustran la limpia historia del Cuerpo de Ingenieros, que es historia del progreso y de la pública prosperidad en España (19).

La Restauración supuso la reafirmación y el apogeo de los cuerpos del Estado, a la vez que se produciría una mayor definición de las fronteras simbólicas y jurídicas de lo público y de lo privado, y la expansión de la iniciativa municipal, sobre todo en las grandes urbes. Los ingenieros del Estado vivieron su posición privilegiada dentro de la Administración como segura y legítima y desde allí emprendieron conquistas individuales de un sector privado en plena expansión, como también de cargos en la Administración local. En comparación con las décadas anteriores al Sexenio, las oportunidades en el sector privado se multiplicaron y las posibilidades de obtener ganancias o salarios altos crecieron, haciendo el sector privado más atractivo para estos funcionarios de élite (20). El fenómeno según el que altos funcionarios del Estado renuncian a su plaza y pasan al sector privado en posición destacada, que los sociólogos franceses denominan pantouflage, no era en absoluto excepcional entre los ingenieros de caminos ni estaba mal visto, como tampoco lo era la vuelta a las filas de empleados públicos. Combinar la noción individualista de poseedor de conocimientos útiles especializados con la posición colectiva de cuerpos como organismos particularmente dotados para defender el bien común creaba un espacio de maniobra enorme para estos hombres, permitiéndoles establecerse entre las élites de la época.

\section{Las Visiones del Estado en la ReVista de ObRas PÚblicas}

En primer lugar se puede constatar que desde el comienzo del periodo analizado, es decir, en los años 1850, aparece ya claramente consolidada una visión que opone el Estado a la libre asociación de los individuos. Asimismo, el Estado se usa a menudo como sinónimo de la Administración central, lo que supone que los municipios y los organismos provinciales se constituyen implícitamente en un tercer espacio con dinámicas propias. Independientemente de sus diferencias sobre las atribuciones del Estado, los ingenieros coinciden en que este

(19) «Parte oficial», Revista de Obras Públicas, 1 (1872), 1-2.

(20) Como ejemplo, véase el caso del ingeniero de caminos Manuel Peironcely, estudiado por LaRrinaga (2007). Sobre este tema también Silva SuÁreZ y LuSa Monforte (2007) o GARRABOU (1982). 
debe defender los intereses públicos frente a los intereses individuales y locales, que pueden ser o no legítimos, pero que siempre son particulares, es decir, no pueden representar el bien común (21). Al mismo tiempo se desarrolla una visión optimista de la sociedad como capaz de potenciar el progreso precisamente gracias al trabajo y a la iniciativa individual, motivados por la persecución de intereses particulares. Independientemente del papel más o menos intervencionista que uno pueda atribuir al Estado, la sociedad se convierte en el motor principal del progreso de cada país:

Las sociedades modernas, $[\ldots]$ han abandonado las huellas de sus predecesoras, para quienes la invasión y el pillaje fueron, en unas, los medios de conquista y adquisición, y la servidumbre, en otras, el fundamento de la conservación y pacífica posesión de aquellas sangrientas conquistas, y [...] han reconocido al trabajo libre como base de su existencia (22).

Algunos plantearon que en las «sociedades modernas», el papel del Estado debía consistir sobre todo en eliminar los obstáculos para las iniciativas de los particulares. Esta postura se inscribía dentro de los planteamientos de la política económica, un discurso y un proyecto que postuló la diferencia fundamental entre lo político y lo civil (23). Como apunta Juan Pan-Montojo, la economía política abogaba por reconstruir el orden social dentro de la lógica de eliminación de los «'obstáculos' que impedían el progreso moral, la emancipación de los sujetos y su interrelación a través de una nueva forma de sociabilidad, cuyo modelo era el libre comercio». Con este propósito articulaba la necesidad de «una profunda intervención política» (24). Desde la Ilustración, muchos

(21) Esta argumentación había sido común también en las décadas anteriores, como se aprecia en el famoso informe del año 1844 sobre cómo se debería impulsar la construcción del ferrocarril en España. La comisión consideraba que lo ideal sería que el Estado se encargase de la construcción de los ferrocarriles, porque su objetivo no es el beneficio financiero, sino «el aumento de la riqueza pública y el bienestar de los gobernados». Dado que los autores del informe preveían que el Estado no iba a querer hacerse cargo de la construcción de ferrocarriles por razones económicas, la intervención de los organismos privados sería indispensable. Con el fin de limitar «las pretensiones, siempre exageradas [de las compañías privadas]» y defender los intereses públicos, la comisión proponía adoptar una política de intervencionismo activo en la construcción y explotación de los ferrocarriles, además de establecer máximas garantías administrativas. Como se puede apreciar en el informe, el ideario de estos ingenieros de la primera mitad del siglo XIX, incluido Juan Subercase, presidente de la comisión y miembro del partido progresista, estaba marcado por un liberalismo alejado en varios aspectos de los principios de la escuela economista. Estos hombres oponían la labor supuestamente desinteresada de los facultativos al servicio del Estado a la iniciativa privada hambrienta de dinero. Informe dado en 2 de noviembre de 1844 por una comisión de ingenieros de caminos de la Dirección General del ramo, y adaptado por ésta al proponer a la aprobación del Gobierno las condiciones generales bajo las cuales se han de autorizar a las empresas de los caminos de hierro. 2 de noviembre de 1844. Gaceta de Madrid, 21 de enero de 1845.

(22) Ángel Retortillo, «Caminos de hierro», Revista de Obras Públicas, 3 (1853): 25-29.

(23) García Monerris (2000).

(24) PAN-Montojo (2014): 53-54. 
gobernantes y pensadores otorgaron al Estado el papel del principal «removedor de obstáculos», aunque hubo diferencias radicales a la hora de definir las políticas que este debía de tomar para conseguir este objetivo.

Durante los años cincuenta y sesenta del siglo XIX se puede identificar una corriente progresista influyente, tanto entre los ingenieros del Estado como entre los ingenieros industriales y agrónomos, desencantados por la falta de resultados materiales de las políticas de fomento desarrolladas por los moderados. Tal como mantiene Fernando Sáenz Ridruejo, el protagonismo de un grupo de ingenieros de caminos en la revolución de Vicálvaro (1854) que llevó al poder a los progresistas, está fuera de toda duda. No solo se ha constatado que la redacción de la flamante Revista de Obras Públicas y el Ateneo de Madrid, frecuentado por algunos de los jóvenes ingenieros, fueron dos importantes plataformas de gestación de la revolución, sino que una vez que esta hubo triunfado, la revista publicó artículos que manifestaban su satisfacción con el cambio político (25). Sin embargo, a pesar del despegue de las obras públicas y del impulso a la enseñanza técnica, el discurso crítico con la corrupción y la ineficacia de la Administración no amainó. Los años sesenta iban a llevar a muchos ingenieros a un cuestionamiento cada vez más radical del papel del Estado desde las posiciones de la escuela economista. En este sentido conectaron con una dinámica de marcado carácter transnacional: el giro hacia el librecambismo que se produjo a partir de los 1850 (26).

Los ingenieros partidarios de la escuela economista, en su mayoría cercanos al progresismo, constituían un grupo que gozaba de gran influencia. En su mayoría no renegaron de los planteamientos desarrollados en las décadas anteriores por sus compañeros, que ensalzaban el papel de la Administración y de los facultativos a su servicio como promotores desinteresados del bien común, pero a la vez mostraron una mayor confianza en el papel que podría desempeñar la iniciativa privada si las leyes eliminaran los obstáculos para su despliegue en vez de entorpecerlo (27). En su crítica de las políticas moderadas de fomento, estos hombres denunciaron la apatía, la legislación inadecuada, la corrupción y

(25) SÁENZ RidRUEJo (1993): 98, 105-106.

(26) CABRILLO (1991).

(27) El Imparcial del 2 de noviembre de 1868, 1, incluye la defensa de la Junta consultiva de caminos, canales y puertos, escrita por uno o varios ingenieros de caminos, en la que se muestra el caso de las compañías concesionarias que en el año 1866 exigieron al gobierno la garantía de interés. Frente a esta reivindicación aparecieron numerosos artículos en la Revista de Obras Públicas «en que se demostró que el Estado nada podía hacer por las compañías en el sentido de la petición, y aunque pudiera, nada debería hacer, y lo que procedía pedir sin sonrojo, era libertad para el comercio, para la industria, para el crédito; que solo la vida y el movimiento comercial, solo un aumento efectivo de riqueza y una más activa circulación, son los poderosos móviles de salvación de aquella ruina. Impresos en un pliego suelto, circularon estos artículos en varias dependencias del Estado, y se repartieron en los Cuerpos colegisladores, en testimonio del levantado espíritu y de la proverbial independencia con que los ingenieros tratan las cuestiones de verdadero interés nacional.» 
la especulación como causas de la falta de resultados tangibles. Plantearon que, lejos de eliminar los obstáculos a la iniciativa de los particulares, el Estado central tal como fue moldeado por los moderados se había convertido en un obstáculo para el progreso, dificultando y sofocando la asociación y el trabajo libre, como también las posibilidades de acción de los municipios (28). Como muestra Florencia Peyrou, esta argumentación sobre la necesidad de limitar algunos poderes del Estado para permitir la «libertad justa» -una noción ligada al influyente krausismo- y el establecimiento de la «armonía natural de los intereses económicos»-de la escuela economista-, lejos de ser monopolio de los progresistas, se generalizó ya desde el año 1856 entre los demócratas (29). Las soluciones que se ofrecían incluían tanto el incentivo a la iniciativa privada a través de las garantías legales, como un papel activo del Estado en el campo de la educación que extendiera los conocimientos útiles para el progreso del país. La influencia de los postulados de la escuela economista entre los ingenieros de caminos fue reforzada por el hecho de que la economía política figuraba en el plan de estudios de la Escuela de Caminos, dentro de la asignatura de Derecho administrativo y Economía política, y fue impartida por apasionados partidarios de la escuela economista como Gabriel Rodríguez (30).

Otros, sin embargo, defendieron un papel más intervencionista para el Estado. De hecho, la llamada a «remover obstáculos» podía perfectamente significar la defensa de un papel más activo del Estado, incluyendo la construcción de vías de comunicación como manera de eliminar los obstáculos para la circulación de personas y bienes. Otros cuestionaron directamente la retórica de la eliminación de obstáculos y promovieron una actitud estatal pro-activa que ayudase al pueblo español a «avanzar por el camino de la civilización» sin que estuviera previsto un punto final, implícito en la noción de «remover los obstáculos», en la cual se intuía un momento en el que todos habrían quedado eliminados.

¿Quién es... tan ignorante que no conozca que los pueblos más adelantados que avanzan ancha y llanamente por el camino de la civilización no solo remueven los obstáculos, sino que prodigan toda clase de auxilios al desarrollo de la riqueza pública, en la que fundan su grandeza y poderío?

Ay de nosotros si dejamos de imitarles! Pues bien, para igualarles, imitemos sus adelantos, y dejando a un lado rancias preocupaciones caminemos sin temor por la senda del progreso material, pues solamente así podremos alcanzar el lugar privi-

(28) Garrido Muro (2006): 209-238.

(29) Peyrou (2008): 438-439.

(30) SÁENZ RidRUEJo (1990): 234. La convicción de la relación entre el carisma de los profesores externos y el peso de la asignatura queda expresada por VICENTE GARCINI, «Reseña Histórica de la Escuela de Ingenieros de Caminos, Canales y Puertos», Revista de Obras Públicas, número extraordinario, 1899. 
legiado que nos señale la Providencia entre los pueblos libres, ilustrados y venturosos (31).

Estas visiones más activas, vinculadas al concepto de fomento, tenían sus raíces en el reformismo ilustrado (32). Redefinidos y multiplicados desde entonces los campos imaginados de la intervención gubernamental, el fomento de la riqueza y de los conocimientos por parte de los poderes públicos fue objeto de un amplio consenso a mediados del siglo XIX. Según afirma Pan-Montojo, desde los moderados hasta los progresistas, desde integristas católicos hasta los demócratas, muchos coincidían sobre la acción pública de fomento que tuviera «un carácter más sistemático, más dirigista y más activo» (33).

Se puede concluir que entre los ingenieros que escribieron en la Revista en los años 1850 y 1860, el papel del Estado como inversor e incluso como constructor estaba abierto al debate, no existiendo un consenso alrededor de él. Es llamativo que el debate sobre el papel del Estado se caracterizara por dos pautas que -a primera vista- parecen contradictorias. En primer lugar, se puede observar todo un abanico de posturas sobre la mayor o menor implicación del Estado en la construcción de las obras públicas. Es decir, las opiniones no se pueden reducir a un enfrentamiento dicotómico entre los defensores del Estado constructor y quienes abogaban por limitar las atribuciones del Estado hasta reducirlo a un mero supervisor y árbitro. Todo lo contrario: en los debates encontramos propuestas de todo tipo, en las que el Estado debe ser (o no) el que decida sobre qué se construye y dónde, debe actuar (o no) como constructor, inversor, árbitro, supervisor, y estos papeles además pueden entenderse como permanentes o de duración pasajera.

Sin embargo, resulta llamativo que este debate se dirimiera en términos de una verdad única, alcanzable a través del conocimiento y del razonamiento científico. La manera de argumentar de una parte importante de los textos implicaba que aquellos que defendían una postura distinta lo hacían por ignorancia o, peor, por mala fe, motivada, seguramente, por intereses particulares. Los términos del debate indican la hegemonía de lo que llamaría el «cientifismo»: la pretensión de que ciertas maneras de organización social y administrativa eran las únicas correctas al derivar de los principios que regían el funcionamiento de las sociedades humanas. A estos podía llegarse «científicamente»: a través de la deducción racional, apoyándose en el conocimiento empírico de los ejemplos reales que ponían en evidencia estos principios. Los promotores de la escuela economista en particular interiorizaron esta noción, planteando su oposición a las políticas moderadas en términos de la ciencia y de la razón frente a la inercia, la ignorancia y la corrupción; pero encontramos este tipo de

(31) Miguel Garriga y RocA, «Memoria que acompaña al plano de la ciudadela de Barcelona y proyecto de su derribo», Revista de Obras Públicas, 3 (1863), 29-34.

(32) Portillo (1998), MartyKáNOVÁ (2013).

(33) PAn-Montojo (2014): 66. 
argumentación también entre los que defendían un Estado intervencionista. No es casualidad que esta visión se desarrollara en paralelo con una manera muy parecida de entender el trabajo del ingeniero, inculcada a los aspirantes durante sus estudios en la Escuela de Caminos, por la que tenían que pasar todos los que quisieran integrarse en el Cuerpo (34). Así, por ejemplo, el ingeniero de caminos Ildefonso Cerdá defendíalos ensanches como una adaptación de las ciudades «a tenor de las prescripciones de la ciencia» (35).

En cuanto a la hegemonía de la visión «cientifista» en los debates sobre el funcionamiento de la Administración, se puede observar un cambio importante durante el Sexenio democrático (1868-1874). Por una parte, el Sexenio supuso el triunfo de las doctrinas laissez-fairistas en el ramo de las obras públicas. La sublevación septembrina se nutría de un ideario complejo, con un mosaico de motivaciones diversas entre los diversos actores sociales. Entre los miembros del Gobierno provisional surgido de la revolución tenía un peso significativo la escuela economista, que desarrollaba las ideas del liberalismo smithiano-la fe en el que el mercado libre y la iniciativa privada son el modo económico natural que mejor garantiza el bienestar material y social. Algunos miembros del Gobierno provisional y de la nueva Administración habían participado en asociaciones cuyo objetivo era promover las ideas de la escuela economista, extrapoladas desde el ámbito económico a toda la sociedad. Profesaban un liberalismo radical, siendo partidarios de la iniciativa privada como base de la economía y de la eliminación de medidas proteccionistas, pero también de la libertad religiosa y la libertad de enseñanza (36). La idea de que la libertad era no solo condición, sino incluso garantía del desarrollo en la política y en la economía, se presentaba como una verdad científica (37). A su vez, los nuevos gobernantes compartían la admiración por una versión idealizada del modelo económico y administrativo inglés, basado en la actividad de los particulares y de los municipios. En el marco de las reformas emprendidas por el Gobierno provisional, los ingenieros «economistas» finalmente pudieron aplicar sus propuestas de descentralización y de liberalización al acceder a los puestos de máxima responsabilidad en el Gobierno central: José Echegaray, como director general de Obras Públicas y luego ministro de Fomento y de Hacienda, y Gabriel Rodríguez, como subsecretario de Hacienda.

(34) MARTYKÁNOVÁ (2014). Más sobre esta institución en RuMEU dE ARMAS (1980) y SÁENZ RIDRUEJO (1993).

(35) ILDEFONSO CERDÁ, «Construcciones civiles. La calle», Revista de Obras Públicas, 5 (1863), 57-60.

(36) Román COLlado (2003): 229-256; Ollero VAllés (1999).

(37) Esta lógica se ve reafirmada, en mi opinión, por el hecho de que los ingenieros no suelen citar a pensadores económicos concretos, por mucho que sabemos de la influencia en sus planteamientos sobre todo de economistas franceses como Say o Bastiat. Al desvincular los postulados de autores concretos, por muy ilustres que sean, se convierten en «verdades» obvias, en principios indiscutibles. Véase también Ramos Gorostiza y Martínez Vara (2008). 
En continuidad con la tradición descrita en las líneas anteriores, los promotores de las reformas basadas en los preceptos del liberalismo radical justificaron sus políticas desplegando un lenguaje cargado de alusiones «cientifistas». Las Bases Generales para la Nueva Legislación de Obras Públicas no dudaron de proclamar su misión de instaurar la «gestión del Estado en este ramo con arreglo a la ciencia y a la razón» (38). Eso no impidió que los ingenieros reivindicaran al mismo tiempo el espíritu práctico, ya que, según su punto de vista, eran precisamente los principios que postulaba la escuela economista los que permitían que este aflorara plenamente:

Un criterio práctico [ . . . de la opinión pública [... ]. Este es el criterio supremo a que obedece nuestra grande y gloriosa revolución; grande y gloriosa por la pureza de las ideas y de las libertades que proclama, y no menos por el profundo sentido práctico que posee, y merced al cual distingue lo remoto de lo próximo, lo que vaga en el porvenir de lo que puede hoy mismo, y ya para siempre, encarnar en la inmediata y palpable realidad. . . tratándose de intereses materiales. . . los pueblos son los verdaderos conocedores y los verdaderos jueces (39).

En general, «las leyes económicas del trabajo humano» se entendían como universales y el deber de los gobernantes era ajustar el aparato legal y administrativo, es decir, el Estado, a estas reglas: «Por importantes que sean las obras públicas, y grandes los intereses que representan, no constituyen una excepción a las leyes económicas del trabajo humano; progresan con la libertad, se paralizan con los sistemas restrictivos, y en la industria privada y en la asociación libre estriban su porvenir y su engrandecimiento» (40).

Con el decreto-ley de Obras Públicas se liberalizó de golpe la construcción de estas. No hacía falta ningún permiso de la Administración para construirlas: el Estado se limitaría a actuar como supervisor y árbitro. No solo se abolía el monopolio del Estado, sino que el Estado renunciaba a la construcción de las obras, salvo en casos excepcionales:

El Estado seguirá construyendo obras, mientras la opinión pública lo exija, pero solo en un caso: cuando una necesidad imperiosa, general, plenamente demostrada lo justifique, y la industria privada no pueda acometer tal empresa; y por si este caso llega, se establecen reglas como garantía contra la arbitrariedad. En oposición a estas restricciones en que al Estado se encierra, la industria privada, la acción libre del individuo, hallarán todas las facilidades compatibles con sagrados derechos que laAdministración no puede en modo alguno sufrir que se atropellen. Cuando una persona, una Sociedad o una empresa, se proponga construir cualquiera obra de las que se comprenden bajo la denominación de públicas, y no pida al Estado auxilio

(38) «Bases generales para la nueva legislación de obras públicas», Revista de Obras Públicas, 23 (1868), 269-271.

(39) Preámbulo del decreto-ley del 14 de noviembre de 1868, escrito por José Echegaray y publicado en AlzOLA Y MiNONDO (1994): 364-368. El decreto-ley está reproducido en MARTínEZ AlCUBiLla (1887): 696-698.

(40) Ibid. 
alguno, ni invoque el derecho de expropiación [.. . ] el Estado no debe intervenir en ella [. . . ]. Toda petición es innecesaria en este caso, toda concesión improcedente, porque el particular o la Compañía usan de un derecho sagrado, y hacerlo respetar, y cuando más impedir por reglamentos de policía que dañe otros derechos (41).

El decreto sobre las bases de la legislación minera y la legislación promulgada en 1869 siguieron pautas parecidas: «En resumen, facilidad para conceder, seguridad en la posesión, deslinde claro y preciso entre el suelo y el subsuelo, son los tres principios en los que se funda este decreto» (42). Como afirma Jordi Nadal, estas normas legales «desamortizaron el subsuelo» yprofundizaron en la apertura a la inversión y la gestión privada, renunciando el Estado en principio ala explotación directa de los establecimientos mineros y estableciéndose concesiones a perpetuidad (43). Otro principio importante de la Gloriosa, plasmado en la normativa legal, era la descentralización. El Estado se desentendió de las obras, contando con que los organismos privados y, sobre todo, los municipios y provincias se harían cargo de ellas. Para tal fin, la ley establecía que los municipios y las provincias podrían actuar como personas jurídicas. Para prevenir prácticas corruptas, quedaron eliminadas de iure las subvenciones, relacionadas con numerosos escándalos e irregularidades.

Los preámbulos de la legislación liberalizadora plasmaron de forma elocuente el ideario de sus promotores. El preámbulo del decreto-ley de Obras Públicas citado anteriormente pretendía trazar un camino para alcanzar el Estado ideal en el que la sociedad se dirigiría por las leyes económicas naturales, liberados los particulares de todos los obstáculos indeseables que se fueron acumulando a lo largo de siglos de tiranía. El preámbulo del decreto-ley de Minas postulaba que introducir el principio de la libertad no solamente resultaría útil porque fomentaba el progreso, sino que además sería de justicia:

No se oculta al ministerio que subscribe que tal vez esta solución radical despierte alarmas en espíritus apocados y sin fe en los grandes principios modernos; pero después de meditarlo concienzudamente, después de consultar la experiencia y de ver los resultados que la reglamentación ha producido en España, y los que la libre acción de la industria privada da en otras naciones, opta sin titubear un punto por la libertad en minería como germen de progreso y prenda de justicia (44).

La visión del Estado esbozada por Echegaray incluía una dimensión histórica que se inscribía en el discurso de progreso de su época. El director identificaba tres fases en la historia de las obras públicas en la Europa moderna.

(41) Ibid.

(42) «Bases generales para la nueva legislación de minas» del 29 de diciembre de 1868, en Martínez AlCubilla (1887): 301.

(43) Expresión de Jordi Nadal. Su análisis en NadAL (1975): 90-93. 299.

(44) «Bases generales para la nueva legislación de minas» en MARTínez AlcubiLla (1887): 
En la primera, el Estado tiene el monopolio sobre las obras públicas, al igual que existe en este tipo de sociedad el monopolio sobre el culto y la enseñanza. Después de esta «realidad opresiva y absorbente» viene una fase transitoria, identificada con el periodo en el que se encontraba el sector en España en esa época. Al final, la sociedad alcanza la cumbre, su estado natural, donde la actividad constructora es plenamente libre y el espíritu emprendedor de cada ser humano puede plasmarse en hechos, llevando al país a un desarrollo que nunca pudiera experimentar bajo cualquier otro tipo de configuración económico-política. Por lo tanto, a pesar de proferir declaraciones de principios en el sentido radicalmente liberal, la legislación concreta y, sobre todo, su aplicación en los siguientes años, no supusieron una retirada total del Estado. Los autores de las leyes mencionadas pretendían emprender la transformación desde el monopolio hacia la libertad plena, pasando por un periodo transitorio en el que el Estado siguiera participando en las obras públicas, aunque fuera de forma reducida.

Esta transición, en el concepto de algunos pensadores, podrá abreviarse; pero fuera empeño vano y aun temerario suprimirla, porque según ellos en las naciones, como en la naturaleza, no hay saltos bruscos, no hay nunca faltas de continuidad.

Y como entre dos direcciones distintas, a menos de choque y ruina, hay una curva de unión más o menos amplia, y entre dos puntos de una línea, a menos de rotura, otros intermedios, así también entre dos sistemas opuestos hay una época de transición, en la cual se aprovecha para el nuevo régimen, y hacia el que, sin bruscas sacudidas, se dirige toda la fuerza viva del periodo precedente, todas sus conquistas, todo aquello, en fin, que a pesar del monopolio se realizó y merezca conservarse (45).

Echegaray establecía un paralelismo entre la nación y la naturaleza, presentando un modelo orgánico de la nación mantenida en movimiento hacia delante por sus fuerzas vivas. Se puede apreciar una confluencia del discurso nacionalista que predica la nación como la comunidad natural por excelencia y el discurso de progreso que establece fases evolutivas para los fenómenos tanto naturales como sociales. Las metáforas del campo de las matemáticas y de la física formaban parte del cientifismo de los librecambistas españoles de los años sesenta, que a su vez pertenecía al bagaje intelectual de los ingenieros alrededor de la Revista de Obras Públicas y de la Revista minera. En todo caso, se trata de un discurso sumamente moderno, según una de las definiciones de la modernidad ofrecidas por R. Koselleck. Un discurso que operaba con conceptos cargados de expectativas, que contenían el proyecto de un futuro mejor, al establecer que existía una forma ideal de organización de la actividad humana en el campo de las obras públicas, una forma alcanzable en el porvenir (46).

(45) Preámbulo escrito por José Echegaray del decreto-ley del 14 de noviembre de 1868, publicado en Alzola y MinONDO (1994): 364-368.

(46) Koselleck (1993). 
Fueron los oponentes de las reformas introducidas en los primeros años del Sexenio quienes, al cuestionar las políticas laissez-fairistas en el ramo de Obras Públicas, renunciaron a la lógica del cientifismo e incluso desarrollaron una crítica abierta de este. Desde el mismo Sexenio aparecieron en la Revista de Obras Públicas artículos en los que se describían los primeros años después de la revolución septembrina como críticos y angustiosos momentos de una reforma inconcebible por lo injustificada y por lo absurda (47). Las reformas liberalizadoras fueron criticadas desde distintas posiciones. Sin embargo, los autores solían coincidir en reivindicar el Estado como un actor necesario que debería desplegar una mayor actividad frente a lo promovido por los reformadores del Gobierno provisional. El que fue uno de los mayores críticos de la reforma echegariana en los últimos años del Sexenio, el ingeniero de caminos Rafael Yagüe, se declaró partidario en general de la misma «escuela económica» que Echegaray, sin que esto le impidiera pretende rrefutar el principio de libertad absoluta en Obras Públicas. Las visiones del Estado ocuparon el núcleo de su argumento en contra de lo que consideraba una reforma inapropiada por exagerada. Yagüe entendía que el rechazo al papel del Estado (entendido en sus textos como la Administración central) derivaba de que este fuera entendido como superior [a los ciudadanos] y como personalidad distinta, mientras en realidad el Estado, del cual [los ciudadanos] forman parte y a cuyo sostenimiento contribuyen, debería entenderse como una representación de la colectividad. Asimismo, resaltaba que la legislación echegariana entendía el trabajo humano solamente como trabajo individual, sin tener en cuenta la colectividad para la que se construyen las obras públicas y por cuyos intereses había que velar. La escuela economista pecaba, en su opinión, de un gran error: pretender que la ley de oferta y demanda tenía una aplicabilidad generalizada y los individuos siempre podían ejercer una elección informada, algo que tachaba de risible. Las obras públicas constituían, para él, un buen ejemplo para poner en evidencia los límites de este ideal.

¿Creéis prácticamente posible que un individuo tiene precisión de trasladarse de una población a otra, entre las que haya establecido, por ejemplo, un ferrocarril, hecho con arreglo a vuestros principios de absoluta libertad, tiene ese individuo los medios, la inteligencia y el tiempo necesario para cerciorarse de si la empresa constructora o explotadora es una empresa formal, si el ingeniero que construyó las obras es verdaderamente inteligente, y las construyó con toda seguridad? ¿Creéis que si no le satisficieran o la probidad de la empresa, o la inteligencia del ingeniero, podría construir otro ferrocarril exclusivamente para efectuar su viaje? (48).

Para Yagüe, la sociedad sí existía y sus intereses deberían ser protegidos por el Estado (central) como su representante. El Estado debería hacerse cargo de lo que le correspondía en la división del trabajo, asumiendo el trabajo social,

(47) «Parte oficial», Revista de Obras Públicas, 2 (1872), 13-14.

(48) RAfael YAGÜE, «Las Bases para la nueva legislación de Obras Públicas de 14 de noviembre de 1868», Revista de Obras Públicas, 5 (1874), 49-55. 
es decir, para la colectividad, ya que ni los individuos ni los municipios y provincias disponen de cualidades necesarias para hacerlo. Al afirmar esto, Yagüe creía distinguir su postura también de la de los socialistas, quienes en su opinión presuponían la bondad y la capacidad de los individuos, por lo que «sus teorías y sus resultados se consideran, con razón, como simples utopías» (49). La desconfianza en los individuos y en su capacidad de gestionar sus intereses, que se desprende de la argumentación de Yagüe, caracterizó, como ha demostrado María Sierra, al liberalismo español de mediados del siglo XIX (50).

Además de cuestionar algunos de los supuestos conceptuales, Yagüe planteó su argumentación en términos de estar presentando observaciones empíricas frente a las teorías de Echegaray. En primer lugar, cuestionó la interpretación histórica de Echegaray que unía la evolución hacia una mayor libertad política con la liberalización de las obras. Según Yagüe, no se podía observar una evolución progresiva ni una conexión entre la libertad política y la liberalización de la construcción. Al menos en España, afirmó Yagüe, había sido precisamente en las etapas de mayor libertad política, cuando el Estado había estado más involucrado en la construcción de estas obras. En general, Yagüe mantenía que cada país mostraba características específicas que requerían distintos modos de actuar. En su opinión, España carecía de un asociacionismo potente, y los municipios y las provincias tampoco podían servir de elemento movilizador: $E l$ principio pugna con la escasa iniciativa individual en nuestro país, y con los escasos medios y dudosa voluntad de las corporaciones municipales y provinciales. En estas circunstancias, no quedaba otra opción que potenciar el papel del Estado central como motor de la modernización, y renunciar a ello por razones ideológicas pondría en peligro el progreso del país. Yagüe no estuvo solo en sus críticas. En general, la argumentación apuntaba a la complejidad de las sociedades humanas y a las peculiaridades de cada país y de cada situación histórica, denunciando como ilusorias las pretensiones de gobernar el país según unas reglas básicas cuya aplicación siempre garantizaría los mismos resultados beneficiosos. Este escepticismo crítico, que de por sí no implicaba necesariamente una visión del Estado determinada y permitía conservar algunas de las medidas introducidas por los librecambistas del Sexenio, logró establecerse como hegemónico durante la Restauración hasta el surgimiento del discurso regeneracionista.

La actividad reformista del Sexenio abarcó un sinfín de ámbitos, en los que se repitieron pautas parecidas. Las nuevas medidas se desarrollaron en un ambiente sumamente conflictivo. En primer lugar, los gobiernos nacidos de la revolución tuvieron que afrontar el dilema que consistía en incentivar distintos proyectos mientras existía la necesidad -y el compromiso explícito- de reducir el gasto público. Además, los constantes cambios políticos contribuyeron a una
(49) Ibid.
(50) SIERRA (2009). 
falta de continuidad legal e institucional que dificultaba -o directamente truncaba- la aplicación de la normativa. En otras ocasiones, la resistencia de distintos sectores con capacidad de presión obligaba a retractarse o a suavizar las medidas adoptadas. Dicho esto, las reformas que liberalizaron el sector de las obras públicas, abriéndolo a la iniciativa privada y descentralizando las competencias, tuvieron un impacto desigual, que sigue abierto al debate entre los historiadores (51).

La Restauración supuso el reforzamiento del poder central del Estado, a la vez que se conservaban muchas de las reformas liberalizadoras del Sexenio. Las primeras Cortes de Alfonso XII aprobaron la ley de 29 de diciembre de 1876, que restableció la dependencia de las obras públicas del Estado (en los niveles central, provincial y municipal), creando una pirámide jerárquica de competencias. El gobierno impuso el control central dentro de un sistema jerarquizado: el gobierno sometía los planes a las Cortes, las diputaciones al Ministerio de Fomento y los ayuntamientos a los gobiernos de provincia. El 13 de abril de 1877 se adoptó la nueva Ley de obras públicas, seguida por toda una serie de medidas legales que regulaban el sector. Los municipios y las provincias se mantuvieron como personas jurídicas, tal como se había establecido en la ley de Echegaray, lo que hasta cierto punto conservaba la descentralización previa, al igual que la pervivencia de las juntas de obras de puertos, cuya creación fue una de las medidas más exitosas del Sexenio en este ramo. Sin embargo, aunque las provincias y los municipios podían construir y explotar, no eran propietarios de las obras públicas. Si bien es cierto que el gobierno promovía medidas centralizadoras en algunos aspectos, España destacaba por tener más autonomía provincial y municipal que otros países de Europa con un modelo parecido de organización de las obras públicas (52).

Los ingenieros de la Restauración coincidían en la reivindicación del papel del Estado en el ramo de obras públicas, dejando abiertas las puertas a todo tipo de arreglos con el sector privado. El énfasis en la intervención gubernamental incluía a menudo una crítica explícita a la escuela economista, subrayando su desconexión con la realidad española y sus efectos disruptivos, a la vez que quedaba oculto hasta qué punto el régimen de la Restauración asumió las políticas introducidas en el Sexenio. Podemos observar estas pautas en un argumento de la época a favor de la intervención directa del Estado central en la construcción de los canales de riego. El texto lleva a cabo una crítica demoledora de lo que llama «los sistemas y escuelas individualistas [...] basados en teorías»,

(51) Costas Comesaña (2000): 134-135. Sobre la continuidad y discontinuidad de la política económica española en la Restauración: SERRANO SANZ (1987); GómEZ MENDOZA (1989): 54-57.

(52) El análisis de la Ley de Obras Públicas del 13 de agosto de 1877 en Alzola y MinonDO (1994): 394-395. Los cambios y las permanencias en cuanto a las Bases generales de obras públicas del año 1868 por una parte y las del año 1876 por otra, están analizados en FRAX RosALES (1996): 524-528. 
desvinculándolas de los ingenieros, lo que suponía ocultar que la misma Revista de Obras Públicas había sido una de las plataformas de promoción de este tipo de «teorías»:

Es cierto que los sistemas y escuelas individualistas que han predominado en los últimos tiempos, y que de la cátedra y del ateneo han logrado infiltrarse en nuestra legislación, han sido hasta el presente barrera formidable opuesta al progreso del riego agrícola; mas si se quiere con decisión franquear semejante barrera; si, prescindiendo de escuelas y sistemas, basados en teorías que no hemos de juzgar, se quiere colocarse en un punto de vista verdaderamente práctico, adoptando el procedimiento de los países que hoy se hallan a la cabeza del progreso, es indispensable que, resuelta y enérgicamente, el Estado emprenda el estudio y la construcción de las obras necesarias para el establecimiento de los riegos, sin recurrir al ineficaz procedimiento de las subvenciones, que vulnerando el propio principio individualista que en esta materia se ha querido que imperase ha sido, sin embrago, por completo incapaz de alcanzar resultado alguno práctico. Si se desea, en materia de riegos, romper de una vez la estéril política de esta última mitad del siglo, a la que lógicamente deben achacarse los resultados negativos y los fracasos alcanzados, preciso se hace también acometer con alteza de miras la resolución de tamaño problema, sin preocuparse con exceso si los capitales que el país va a invertir reportarán directamente un interés más o menos elevado, pues el efecto útil [...], hay que medirlo de otra suerte: hay que valorarlo por el acrecentamiento de la pública riqueza, que trae aparejado el bienestar y la fortaleza de los pueblos. Si no se hubiese aplicado el criterio que aquí se aconseja, a la construcción de carreteras, a la de los puertos y aun a la de ferrocarriles, tanto en España como fuera de ella, estas obras, que no producen beneficios más generales que los que puedan proporcionar los riegos, es seguro que hoy no existirían. Sigamos, pues, en este punto las verdaderas tradiciones españolas, que nos enseñan que el poder y la protección de los monarcas han sido casi siempre el origen de nuestras antiguas obras de riegos, costeadas algunas de ellas por completo por el Tesoro Real; y si, a semejanza de lo que hacen razas que bien podemos calificar de más prácticas que la nuestra, tal proceder exige que se apoye en brillantes teorías políticas, establézcanse estas $a$ posteriori, siguiendo un proceso inverso del empleado, con lo cual a buen seguro que los resultados que se obtengan serán más favorables (53).

Los ingenieros de caminos vinculados al Estado se distanciaron decididamente de los principios de la escuela economista en lo que tenía que ver con el poder del Gobierno central para decidir las políticas de obras públicas del país. Su visión del Estado se particularizó, resaltando la situación específica de cada país, tanto en términos de tradiciones y evolución histórica, como en lo referido al «espíritu nacional» o a las particularidades de cada «raza». Sin embargo, asumir esta postura que podría definirse como «relativista», no significaba renunciar del todo a apoyar las propuestas concretas en razones «científicas». La identidad de los ingenieros y su discurso de legitimación profesional estaban

(53) «Ingenieros de caminos, canales y puertos. Sus proyectos», Revista de Obras Públicas, número extraordinario (1899), páginas sin numerar. 
demasiado vinculados a la posesión exclusiva de conocimientos entendidos como científicos como para que los ingenieros de la Restauración abandonasen del todo el recurso a la razón técnica en los debates sobre la acción gubernamental.

Se puede decir que mientras los ingenieros del Estado en su mayoría siguieron dando la bienvenida a la iniciativa privada, siempre que el Estado mantuviera el control sobre los trazados y el poder de supervisión, las líneas divisorias se fueron estableciendo sobre todo alrededor del reparto de las atribuciones entre el poder central y los poderes públicos locales y regionales. Sin dejar de criticar el librecambismo del Sexenio, muchos ingenieros con fuertes lazos regionales, como por ejemplo Pablo Alzola, que fue alcalde de Bilbao y presidente de la Diputación Provincial de Vizcaya, reivindicaron la descentralización y la iniciativa municipal y provincial como motor del progreso y desarrollaron una visión mucho más optimista que en su momento el ingeniero Yagüe, sobre la voluntad y la capacidad de los ayuntamientos y de las diputaciones provinciales para lanzar y llevar a cabo proyectos de obras públicas (54).

\section{CONCLUSIÓN}

Los ingenieros de caminos participaron durante la segunda mitad del siglo XIX en diversas corrientes políticas, e hicieron de su revista corporativo-profesional un espacio en el que construir y reproducir sus visiones de Estado y también dirimir sus conflictos sobre ellas. Desde allí, definieron y defendieron sus posturas como ingenieros, apoyándose en la legitimidad tecnocrática, es decir, derivada de sus conocimientos especiales. Sus argumentos fueron escuchados, difundidos, utilizados y criticados en otros periódicos de la época, desde otras revistas especializadas hasta la prensa dirigida a la «opinión pública» general.

El Estado, generalmente entendido como la Administración central, aparece en sus visiones opuesto a la libre asociación de las personas y también como un aparato que debe velar por el bien común, por el «verdadero interés nacional», y fomentar la riqueza del país. Allí termina el consenso sobre sus funciones. La pluralidad de opiniones sobre las atribuciones del Estado estaba ligada a la militancia de cada ingeniero en las distintas corrientes políticas de la época, oscilando entre el Estado como removedor de obstáculos para la libertad y para la iniciativa de los particulares hasta la defensa de un Estado muy activo, que decidiera, invirtiera y construyera. No obstante, la gran mayoría de los ingenieros de Estado coincidía en la importancia de los cuerpos de ingenieros en las circunstancias de la época y en el hecho de que su organización particular les dotaba de cualidades que les capacitaban para representar al Estado de forma más

(54) Alzola y Minondo (1994). 
correcta, virtuosa y eficaz que la mayoría de los empleados públicos de la época.

En cuanto a los pilares del discurso profesional, se observa una gran continuidad a lo largo de la segunda mitad del siglo XIX, haciendo hincapié en el progreso material y el proceder científico, opuesto a la rutina. No obstante, trazando las visiones del Estado en concreto, podemos observar mayores fluctuaciones. Destaca la importancia de las corrientes progresistas y de la escuela economista en los años 1850 y 1860 , que ponían un énfasis decisivo en el que el Estado no debería obstaculizar la iniciativa privada y local, sino eliminar los obstáculos para la misma, ya que la libertad permitiría el progreso de la civilización y el aumento de la riqueza del país. El Sexenio democrático aparece como culminación de estas tendencias, a la vez que surgen críticas demoledoras a las repercusiones que pudieran generar las políticas de liberalización y descentralización. La reivindicación del papel del Estado durante la Restauración suele venir acompañada por las críticas a las «teorías» del liberalismo radical, sin que eso impidiera promover la iniciativa de los poderes locales y de los particulares. Un nuevo giro - que ya queda fuera de esta investigación- se produjo al final del siglo XIX y sobre todo a principios del XX, cuando se articuló el discurso regeneracionista que reclamaba una intervención a gran escala por parte del Estado para acelerar la modernización, tal como se observa en el conocido «debate hidrológico». A pesar de estas diferencias, se puede afirmar que durante la segunda mitad del siglo XIX, la vinculación entre el Estado y las obras públicas se consolida hasta mostrarse inexorable. Este vínculo se observa también en el imaginario social español de la época y sitúa a los ingenieros en una posición particularmente ventajosa. Analizar la reproducción de esta posición a lo largo del siglo Xx ya sería un tema para otros trabajos (55).

\section{BIBLIOGRAFÍA}

Alzola y Minondo, P. (1994) [1899]. Historia de las obras públicas en España. Madrid: Colegio de Ingenieros de Caminos, Canales y Puertos.

Cabrillo, F. (1991). El nacimiento de la economía internacional. Madrid: Espasa.

Camprubí, L. (2014). Engineers and the Making of the Francoist Regime. Cambridge, Mass.: The MIT Press. Disponible en: http://dx. doi. org/10. 7551/mitpress/9780262027175.001.0001

Costas Comesaña, A. (2000). Los progresistas como motor del cambio económico. En AA. VV. Sagasta y el liberalismo español (pp. 123-135). Madrid: Fundación BBVA, Madrid.

Frax Rosales, E. (1996). Las leyes de bases de obras públicas en el siglo XIX. Revista de Estudios Políticos, 93, 513-528.

(55) Véase por ejemplo, CAMPRUBí (2014). 
García Monerris, C. (2000). Las utopías civilizatorias del capitalismo pensado. Historia y Política, 4, 209-229.

Garrabou, R. (1982). Enginyers industrials, modernització econòmica i burgesia a Catalunya (1850 - inicis del segle XX). Barcelona: L'Avenç/Collegi d'Enginyers Industrials.

Garrido Muro, L. (2006). 'Un monstruo cálido'. El proyecto de Estado del progresismo. En M. Suárez Cortina (ed.). La redención del pueblo. La cultura progresista en la España liberal (pp. 209-238) Santander: Universidad de Cantabria.

Gómez Mendoza, A. (1989). Ferrocarril, industria y mercado en la modernización, Madrid: Espasa Calpe.

Koselleck, R. (1993). Futuro pasado. Para una semántica de los tiempos históricos. Barcelona: Paidós.

Larrinaga, C. (2007). El ingeniero de caminos Manuel Peironcely (1818-1884). Modernización y obra pública en la España del siglo XIX. Bilbao: Euskadiko Portu, Ubide eta Bideetako Ingeniarien Kolejioa.

Lusa Monforte, G. (1994). Industrialización y Educación: Los ingenieros industriales (Barcelona 1851-1886). En R. Enrich et al. (eds.). Tècnica i Societat en el Món Contemporani (pp. 61-78). Sabadell: Museu d'Història de Sabadell.

Martínez Alcubilla, M. (1887). Diccionario de la Administración española, vol. 7.

Martykánová, D. (2007). Por los caminos del progreso. El universo ideológico de los ingenieros de caminos españoles a través de la Revista de Obras Públicas (18531899). Ayer, 68, 193-219.

- (2010). Los ingenieros en España y en el Imperio otomano. Una historia comparada [tesis doctoral inédita]. Universidad Autónoma de Madrid, Madrid.

- (2013). El discurso de fomento y las políticas tecno-científicas de la Corona española en el periodo comprendido entre los años 1790 y 1808 . Estudio de caso de los instrumentos y libros para la expedición a Guantánamo. En J. Martínez Millán, C. Camarero Bullón, M. Luzzi Traficante (coords.). La Corte de los Borbones: Crisis del modelo cortesano, vol. III (pp. 1619-1634). Madrid: Polifemo.

- (2014). Shaping a New Man:The Schools for the State Engineers in NineteenthCentury Spain (1830s-1900). Engineering Studies, 7, 87-107.

Nadal, J. (1975). El fracaso de la Revolución industrial en España (1814-1913). Barcelona: Ariel.

Ollero Vallés, J. L. (1999). El progresismo como proyecto político en el reinado de Isabel II, Práxedes Mateo-Sagasta, 1854-68. Logroño: Instituto de Estudios Riojanos.

Pan-Montojo, J. (2014). Progreso material, fomento y libertad: la economía en las culturas políticas del periodo isabelino. En M. C. Romeo y M. Sierra (eds. ). La España liberal, 1833-1874 (pp. 51-87). Madrid/Zaragoza: Marcial Pons/Prensas universitarias de Zaragoza.

Pan-Montojo, J. yMartykánová, D. (2012). State-Builders:State Engineers and Modern Governance in Spain, 1830-1900. Ponencia presentada en el congreso anual de laAmerican Historical Association, Chicago, 3-5 enero de 2012.

Peyrou, F. (2008). Tribunos del pueblo. Demócratas y republicanos durante el reinado de Isabel II. Madrid: Centro de Estudios Políticos y Constitucionales. 
Picon, A. (1992). L'invention de l'ingénieur moderne. L'École de Ponts et Chaussées 1747-1851. París: Presses de l'École nationale des Ponts et chaussées.

Portillo Valdés, J. M. (1998). Política. En V. Ferrone y D. Roche (eds.), Diccionario histórico de la Ilustración. Madrid: Alianza Editorial.

Ramos Gorostiza, J. L. , y Martínez Vara, T. (2008). Las ideas económicas de los ingenieros de caminos: la Revista de Obras Públicas (1853-1936). Investigaciones de Historia Económica, 11, 9-38. Disponible en: http://dx. doi. org/10. 1016/S16986989(08)70152-8

Román Collado, R. (2003). La escuela economista española. Cádiz/Sevilla: Universidad de Sevilla/Universidad de Cádiz.

Rumeu de Armas, A. (1980). Ciencia y tecnología en la España ilustrada. La Escuela de Caminos y Canales. Madrid: Colegio de Ingenieros de caminos, canales y puertos/Turner.

Sáenz Ridruejo, F. (1990). Los ingenieros de caminos del siglo XIX. Madrid: Colegio de Ingenieros de Caminos, Canales y Puertos.

- (1993). Los ingenieros de caminos. Madrid: Colegio de Ingenieros de Caminos, Canales y Puertos.

Serrano Sanz, J. M. (1987). El viraje proteccionista en la Restauración. La política comercial española, 1875-1895. Madrid: Siglo XXI.

Sierra, M. (2009). 'La sociedad es antes que el individuo': el liberalismo español frente a los peligros del individualismo. Alcores, 7, 63-84.

Silva Suárez, M. y Lusa Monforte, G. (2007). Cuerpos facultativos del Estado versus profesión liberal. En M. Silva Suárez (ed.). Técnica e ingeniería en España, vol. 4, El ochocientos: pensamiento, profesiones y sociedad (pp. 323-386). Zaragoza: Real Academia de Ingeniería/Institución 'Fernando el Católico'/Prensas Universitarias de Zaragoza. 
